\title{
Internet Technologies course with combined professor and on-line contents methodology
}

\author{
Eduardo Magaña, Daniel Morató \\ Department of Electrical Engineering and Computer Sciences \\ University of California, Berkeley, CA 94720 \\ email: \{emagana,dmorato\}@eecs.berkeley.edu
}

\begin{abstract}
In this paper we present the experience and results in the teaching of a course titled "Internet Technologies". This course, offered in Public University of Navarra (Spain), uses a special methodology that combines in-classroom lectures in front of computers with on-line contents. The students work on the on-line course lesson at the same time that the professor is available in the classroom to help the students during the hours assigned to the course. The tool used to manage the on-line contents, tests, exercises and grades, was designed specially for this course. It incorporates a student profile classification based on the time used to solve the tests.
\end{abstract}

Keywords-Distance course, presential professor, e-learning tool

\section{INTRODUCTION}

The importance of on-line courses has grown these last years, in part thanks to the impulse from important universities [1] [2] and enterprises [3]. These on-line courses use the usual paradigm of on-line contents, exercises and tests, having the possibility to ask questions to the tutors of the course using email or discussion forums. This paradigm has some problems that we will analyze in this paper as low interactivity and low student motivation [4].

We present the experience and results in the teaching of a course using the paradigm: combined presential professor and on-line contents. This methodology tries to join on-line and presential learning. It has been tested in the teaching of a course titled "Internet Technologies" offered in Public University of Navarra (Spain). The advantages of this proposal will be shown in this paper and the best indicator is the high level of success in the grading of the students.

This experience uses an e-learning tool developed specially for this course. This tool (called PLE, Presential Learning and Evaluation) provides functionalities similar to existent tools (on-line contents, tests, exercises, forums, email interaction with the professor, etc.) but incorporates some singular characteristics. First, the students can access their grades whenever they want, so they can get quick information about how they are following the course in real time. Second, the test grading takes into account not only the correct answers but also the time used for the students to complete the test. Previous tools only fix a maximum time to finish the tests but don't take into account this time to grade the student [5]. This new parameter provides results that will be analyze in this paper and it allows to distinguish between different student profiles based on the techniques

This research was made during 2000-2001 at Public University of Navarra that they use to answer the tests. In order to use the time parameter to grade the tests, we need to establish some thresholds, and the student profiles will be useful to such a task.

The combined on-line contents and presential class provides more motivation for the students. We have checked how with this methodology the number of students that succeed in the course is higher than with normal on-line courses. We show that the students prefer to ask directly to the professor instead of using forums or email tools. It is much easier for the student to express his doubts this way because it allows more interactivity with the professor.

\section{The COURSE: InTERnet TeCHNOLOGIES}

The course is an introduction to new technologies, telecommunications and Internet access and use. The first lecture explain the basic knowledge about computers (main parts, internal representation of information) and computer networks (local area networks, Internet, TCP/IP). Then some lectures are dedicated to Internet services like web browsing and electronic mail, explaining its utilization from the user's point of view. Next lectures are dedicated to explain how a user can get an Internet connection, explaining the different technologies available in the access loop (telephone modem, RDSI, ADSL, cable modem, etc.) and the types and services offered by an Internet Service Provider (ISP). The student receives the main principles to choose the ISP and the technology for the access loop. Then some lectures are dedicated to explain other Internet services like File Transfer Protocol (FTP), newsgroups, Internet Relay Chat (IRC), Telnet/Secure Shell (SSH), video-conference, etc. Finally, an overview of several programming languages for web creation and the way to publish web pages on-line are shown.

The "Internet Technologies" course is offered to students from any major. In the last two years that this course has been offered there has been an average of $67 \%$ from engineering (electrical and electronic, telecommunications, etc.), $23 \%$ from bussiness careers and $10 \%$ from social studies. This course has 2 days of 2 hours per week. The evaluation is continuous and based on tests and exercises at the end of each lecture. The tests are automatically corrected by the PLE tool and the exercises are reviewed by the professor. The grades corresponding to tests and exercises appear in the PLE tool in realtime for the tests and as soon as the professor finishes the revision for the exercises. The class- 


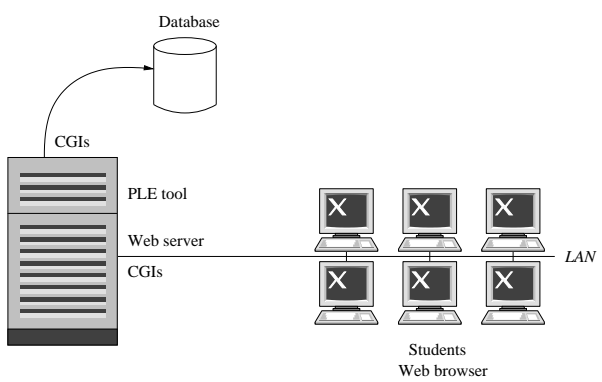

Fig. 1. PLE architecture scheme

room is equipped with 46 computers with Linux operating system and a projector. The first weeks the professor is in charge of explaining the fundamentals to follow the course (linux basics, web browsing and email fundamental ideas), and after that the combined professor and on-line contents paradigm explained in section IV is used.

A clear evolution has been observed these last years in the background knowledge of students. We have observed how the fast introduction of Internet to the general public in the country has changed the background of the students. As an example, in the academic year $2000 / 2001$ only $10 \%$ of the students had email at the beginning of the course but this figure grows to $33 \%$ in the 2001/2002 course. This means that each year the students have more knowledge about how to use these technologies, but it doesn't mean that they understand its internal working procedure, the security problems or how they can get better results from its utilization. Therefore the course is changing, adapting to this phenomenon, giving less importance to the explanation of the utilization of Internet tools, and giving more importance to the explanation of the internals of the technology and the tricks to make a good use of it. The custom e-learning tool has helped in this task, making it easy to adapt the contents for the course.

\section{THE E-LEARNING TOOL: PLE}

The PLE (Presential Learning and Evaluation) tool was designed for this course and uses a web browser as the interface with the user. In the server side, a web server able to run CGIs (Common Gateway Programs) and a simple database are used. This server has been implemented on Linux to offer a low cost platform. The hardware is a two PentiumII $350 \mathrm{MHz}$ server with $256 \mathrm{MB}$ RAM and a 40GB SCSI hard disk. All the software has been written in $C$ language to get better performance, specially during peaks of utilization like at the beginning and end of the class. This optimization allows the use of a low cost hardware platform. A scheme of the system appears in figure 1.

The user interface has been simplified as much as possible because we need a practical interface with all the functionalities accessible at every moment. This means to reduce the overload of graphics and use a simple scheme of frames with a basic toolbar always present.

The tool incorporates different functionalities already available in similar tools like WebCT [6][7], Lotus Learning Space [8] and many others [5] [9]:

- Course contents on-line, including images and videos

- Discussion forum

- On-line evaluation (tests and exercises)

- Possibility for the students to see their grades as soon as a test is submitted.

One special characteristic of this tool is the authentication scheme. As all the students need an account to log into the Linux machines, we didn't want to use another account (user and password) to make the course authentication. More passwords mean a higher probability of forgetting them or mixing both accounts. So the PLE tool uses the same account to authenticate the students than they use for logging into the machine. This scheme makes all the administrative burden with the student accounts easier.

Although the tests are corrected on-line by the tool, the exercises have to be sent to the professor to be reviewed. The professor has an special administrator interface that allows to grade these exercises or interact with the system (delete or edit messages in the forum, modify on-line contents, obtain more information about the evolution of each student, general grades summaries, etc.).

The PLE tool incorporates a special characteristic compared with other tools like WebCT: the time consumed to complete each test is used to evaluate the students. The evaluation procedure tries to avoid situations where the students just try to search for the answer in the course content without having read it before. If the students try to do this they are going to use more time to complete the test and it can be detected by the system. We present some analysis and results on this evaluation method in section V. We look for different student profiles based on their studying and test answering patterns. These profiles can help us on adapting the content and methodology of the course.

Besides the PLE tool has a complete control over the test environment. It can control whether it is the first time the student is completing the test or not, and it takes into account only the first try for grading. If there is any mistake in the procedure (for example a student that doesn't finish all the questions of a test) a corresponding entry is stored with the grade of the test. Sometimes these special cases will require the intervention of the professor. An easy administration interface helps in this task.

Finally, a technique has been implemented that makes impossible to search in the course contents using the typical utility available in web browsers. This will be useful to avoid the students to search for key words for answering test questions.

\section{COMBINED PROFESSOR AND ON-LINE CONTENTS PARADIGM}

All the contents for this course are on-line: the web pages offer exactly what the professor would teach in a lecture and there are exercises and tests to complete the evaluation. The on-line contents are only accessible during the hours assigned to the course. An automatic mechanism activates 
the contents only during these hours, so the professor is liberated of this tedious task. Besides, these contents are only accessible by computers in the classroom where this course is taught. Compared to ordinary on-line courses, the students have to attend to certain classroom in certain timetable and the professor will be present during these hours in the same classroom. The system does not replace the teacher and he will be involved in the learning process as a fundamental piece [10]. The methodology of this course was designed as an experiment that tries to discover the amount of student performance that a professor could add to the electronic contents and tools. We think that the presence of a professor, like in a presential class, will help in the learning process of the student.

This paradigm offers some advantages:

- The web pages offer exactly what the professor would teach in a lecture. It allows different learning rates for each student depending on his abilities or his previous background.

- The system includes multimedia contents, images and video with student interaction. This provides a good multimedia learning platform.

- The professor spends all his time during the lecture hours of the course on solving problems and doubts that the students have.

- Greater motivation for the student: there are some fixed hours to follow the course and he is going to have always the help from the professor.

- It provides a way to assure that tests and exercises have been done by the students themselves, without any external help. This is impossible to control in ordinary on-line courses.

Compared with traditional (not on-line) lectures, with this methodology the whole lecture time is dedicated to solving the doubts that the students find as they study. Compared with on-line in-home courses the students have direct communication with the professor instead of relying on slow (email, chat) communication systems that make it more difficult to explain some doubts.

One of the main characteristics of classical on-line courses is the freedom the students have to design their studying schedule. However, one problem appears and it is the poor motivation of the students. The figures for the last course 2001/2002 in Public University of Navarra is that no more than $40 \%$ of the students finish these on-line courses. The cause of these bad results is the low motivation of the students because of the absence of presential classes and the lack of presential teacher. At the same time the students put these courses in the lower possible priority because of the absence of a rigid timetable.

With the new paradigm proposed in this paper we get the best of both on-line courses and traditional presential courses. In one hand we have all the contents of the course on-line, that adapts easier to the different learning rates for each student. On the other hand, the presential teacher creates more interactivity and makes easier to solve the doubts than with the on-line courses (using electronic email or dis-

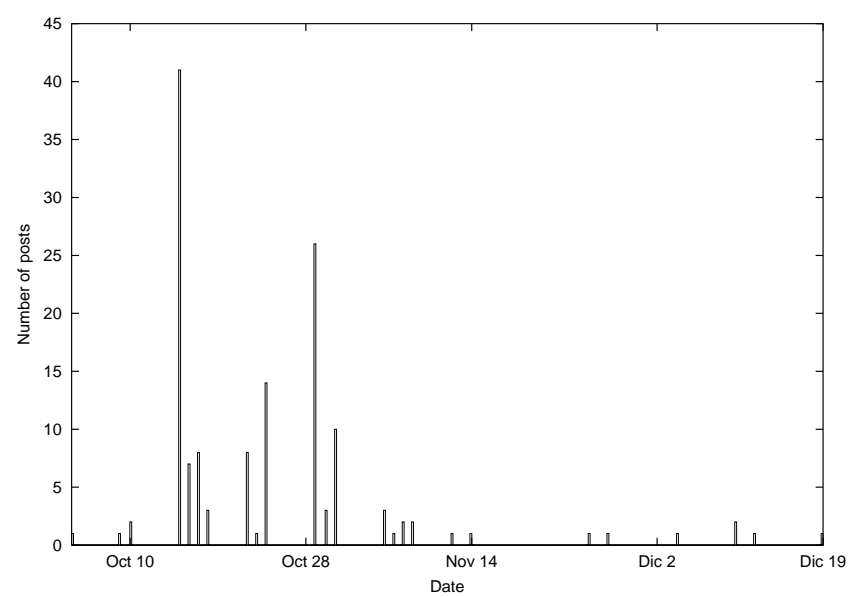

Fig. 2. Time series of posted messages in the discussion forum

cussion forums).

We have analyzed this last interaction student-professor in our course. If the student can choose, he prefers to ask the professor directly face to face than writing an email or posting a message in the forum explaining his doubt and waiting for the answer [11] [4]. One reason for this is that the student receives the answer faster if he can talk to the professor directly, but the most important reason is that it is much easier to express some doubt talking to the professor than by the other electronics methods. Talking to the professor the student can explain and detail his doubt in a much easier way than by electronic methods. Normally, the same interaction using electronic methods would require to interchange several messages between the student and the professor, making the process more tedious.

To demonstrate this, we have observed the following in our course. Electronic email is used by the student only to send the exercises and very occasionally to ask any question. The discussion forum is only used when its use gives some points to the student or it is required to complete some exercise. When they are required, its utilization is $100 \%$. However, in the rest of the course when its use is not graded, the level of participation is very low, tens of times less used than direct interaction with the professor. Finally, talking to the professor in person is the preferred option with large difference. For example in the last year, if there were about 600 questions to the professor in person, there were only 20 questions in the forum and 5 emails.

In figure 2 we present the time series of posted messages in the forum. The two big peaks of October 15 and October 28 corresponds to exercises (and not questions to the professor) where the participation in the forum was graded. For the rest of the course we observe how the participation is very low as we have commented before.

However with the proposed methodology, the motivation of the students is very high, and the interaction with the professor and other students is also very good. This way $94 \%$ of registered students for that course last year finished 
the course and obtained the final grade.

Finally, as the professor is walking around during the classes, the students have to do the tests and exercises by themselves, only accessing the course materials if they need them. So, the students are enforced to make their best and their grades are going to be more related to their real knowledge. In ordinary on-line courses, the results from tests and exercises is not final because the students can transfer information between themselves or with a third people, so in these on-line courses it is usual to have a final presential exam. With our proposal, this final exam is not necessary and the tests and exercises provide accurate data to grade the students. Our test course, for example, uses only these tests and exercises to grade the students, without any final exam. With this procedure the student is more satisfied because his work all along the semester is evaluated and taken into account.

However, this paradigm has its drawbacks. The most important is that the effort from the professor is greater compared to other paradigms. He has to prepare the on-line lectures, exercises and tests, and at the same time he has to work with the students, getting involved in the learning process. Although this means more work for the professor it means a better utilization of professor's capabilities and the results are very encouraging.

\section{STUDENT PROFILES BASED ON THEIR STUDYING AND TEST ANSWERING PATTERNS}

In this section we use the functionality of measuring the time that a student uses to complete a test. We analyze the results and observe how we can distinguish different student profiles. Indeed, we have noted two main behaviors when the students answer a test. One group of the students first study the lecture and then try to answer the questions in the test. But there is always another group of lazier students that try to complete the test without studying the corresponding lesson or only with a quick reading. This means that these students, at the same time that they are doing the test, are going to try to find the answers looking back at the course materials. This means that they are going to use much more time to complete the test than the students from the first group. Therefore, we can use the time parameter to distinguish between these two student profiles. Later we can use these profiles to determine the threshold to grade the time used for test completion. We want to penalize those students that take too much time to complete the test.

In figure 3 we can see a typical histogram of the time used to complete a test. The test presented in that figure is from the last year course, with 78 registered students that work in couples to complete the tests, getting 40 couples (two single students) that appear each one as one student in the figure (we will analyze each pair of students as an only one student in all this paper).

We observe that there is an important percentage of students $(36 \%)$ that finish the test with the minimun time and from that point we observe a tail of students that use more time to finish the test. This means that the first peak of

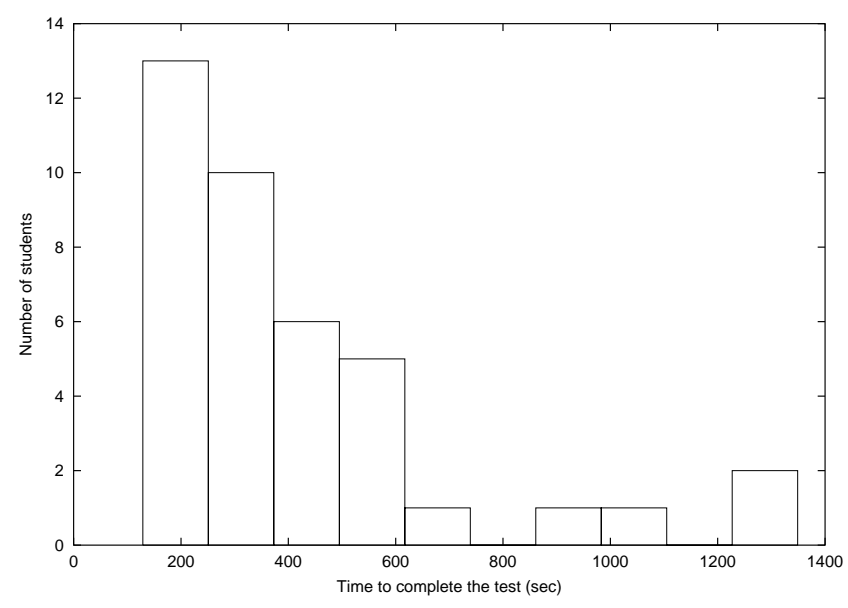

Fig. 3. Histogram of test completion time per student

minimun time corresponds basically to students that have studied the course materials and are not looking for the test answers in that material while they are doing the tests. The next bars indicate students that look for some answer in the course material. Finally, the students that make a search for almost all the test answers in the course materials appear at the end of the tail. We must note that these students use up to 6 times more time than the first students. This pattern is repeated in all the tests in a similar way, so we can use this figure to decide the threshold from which the students will have a reductions in their grades because of their slowness. In our case we could choose a figure around 300-400 seconds to start the reduction, or we could use a gradual reduction from the 200 seconds point for this test.

The average and standard deviation taking into account all the tests of last academic year are presented in figure 4. We observe the same pattern in it, allowing to distinguish the two extreme student profiles:

- Profile A: students that study the lecture and try to answer all the test questions without looking again at it.

- Profile C: students that try to answer the test questions looking at the course materials and without any previous study.

Between these two profiles we find the big group of students in a intermediate situation (profile B). They study the course material, but when they answer the test questions they can look back at the materials to secure some data, in a more or less usual routine. As we are using tests with short questions, the students quickly know or don't know the answer. If they are spending much time solving the test it must be because they are searching for the solutions. To check this theory, we tracked those students that use too much time to complete the tests. These students are usually the same for all tests. We have seen how they use the method of searching all the answer in the course materials. It is clear that these students are not acquiring the knowledge required by the course, so their grades have to reflect this fact.

These profiles can be distinguished per test as we have 


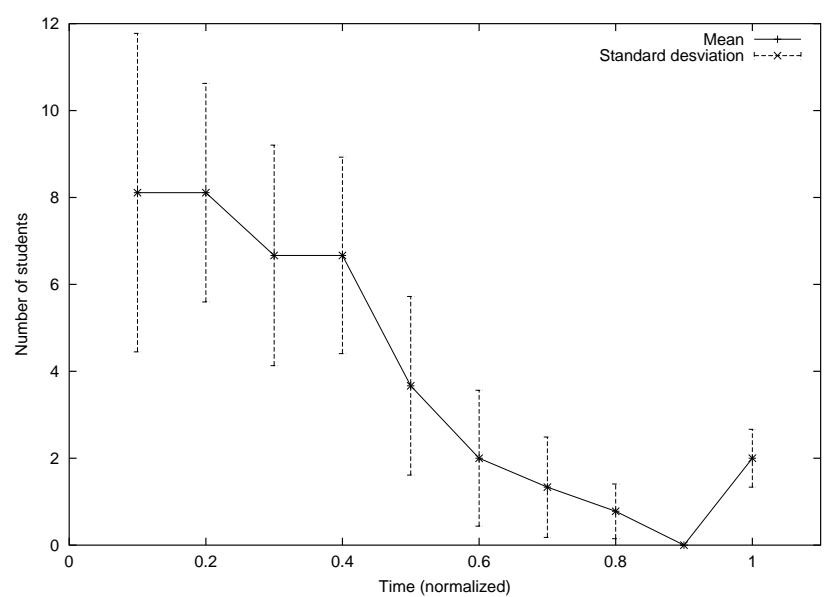

Fig. 4. Mean and standard deviation from histograms of all the tests

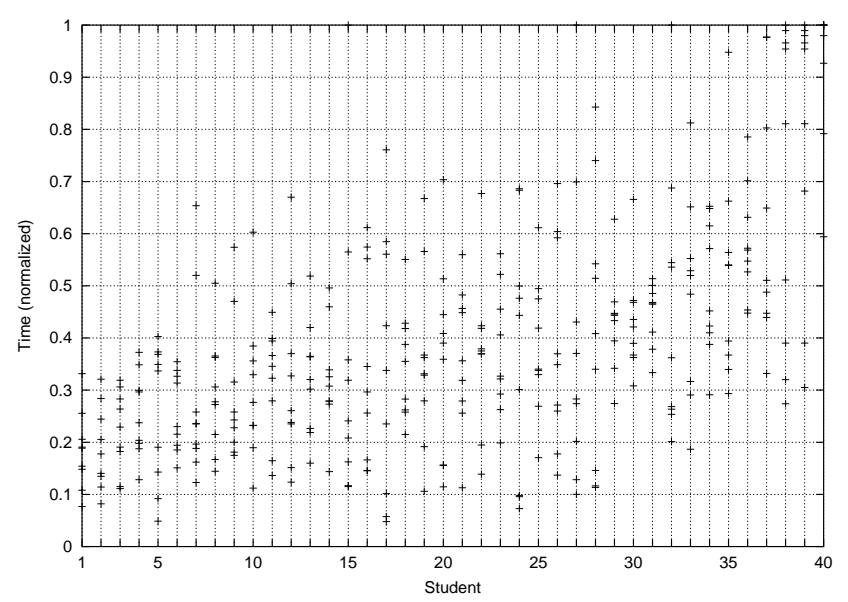

Fig. 5. Test completion times per student

seen. But we would like to analyze if the students keep more or less the same profile for all the tests. Figure 5 shows the completion times for all students (40) and all tests (9) of the course. Students are ordered based on the average completion time for all the tests. The times are normalized in order to compare the different tests that have different number of questions and different difficulty. In that figure student 1 for example belongs to profile A clearly while student 40 can be classified in profile $\mathrm{C}$ without any doubt. Although there is great variability in the results for each test, most students can be classified in these profiles. The rest of students, with more variable study patterns, presents different results for each test and are very difficult to classify as for example student number 17 on figure 5 .

The rule used in this course to grade the students was the following. For each test, we calculate the histogram as figure 3 and we calculate the $10 \%$ percentile of that distribution. We take this value as a threshold. Then we apply a linear factor from this threshold to all the other students. This linear factor reduces the grade of the student, more if

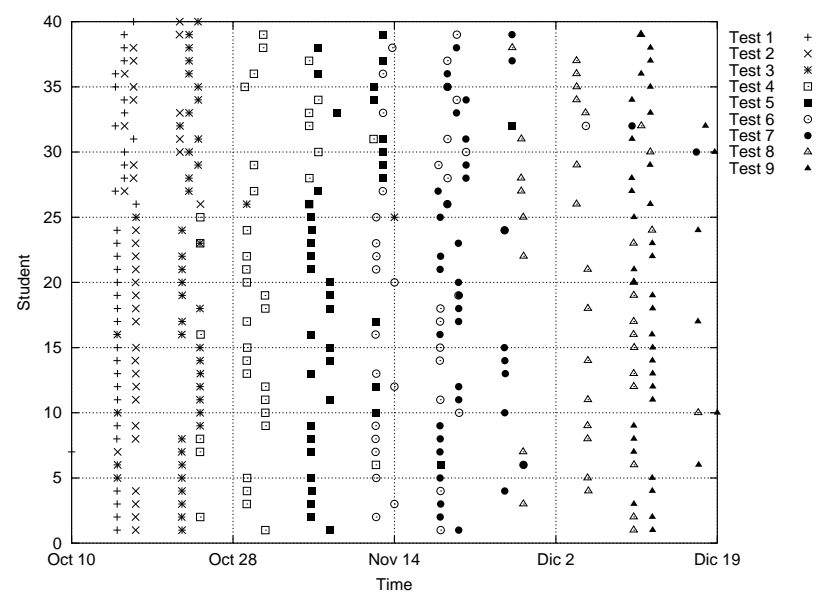

Fig. 6. Chronograme of test completions per student

the completion time for that student is bigger. This reduction can be as bigger as $30 \%$ for the slowest student for example.

\section{COURSE TRACKING}

One interesting aspect to analyze in the educative cycle is the different learning speed per student. With the methodology proposed in this paper, each student can review the lectures at the pace he wants. In our course, the different lectures have some scheduling, making public the contents of each lecture in certain dates. This gives a guide to the students to know if they are getting delayed. Besides, it provides a way to encourage advanced students to deep into the course contents, and make the exercises better.

Figure 6 presents the chronograme of test completions for each of the students and tests. We observe how for most of the tests all the students complete them around the same day. Only for some tests like 6, 7 and 8 the completion time is more spread. This pattern can be observed better in figure 7 that represents the average and standard deviation in test completion date for each of the tests. Besides we can check how there are students that don't follow the normal order of lectures when they are solving the tests, although these order variations are minimal.

In figure 7 we can see the progressive advance in finishing the tests. This figure shows that the course lectures are reviewed by the students at the same pace. Besides, the deviation in these times is not too high. This reinforces the idea of good advance by the students.

\section{CONCLUSIONS}

An experiment of a paradigm of "presential professor with on-line contents" has been presented in this paper. Among the benefits of this methodology we can highlight the better interaction between student and professor, and the greater motivation for the students to keep on with the course. A better adaptation to the student learning rate is possible, because all the course lectures are on-line. These 


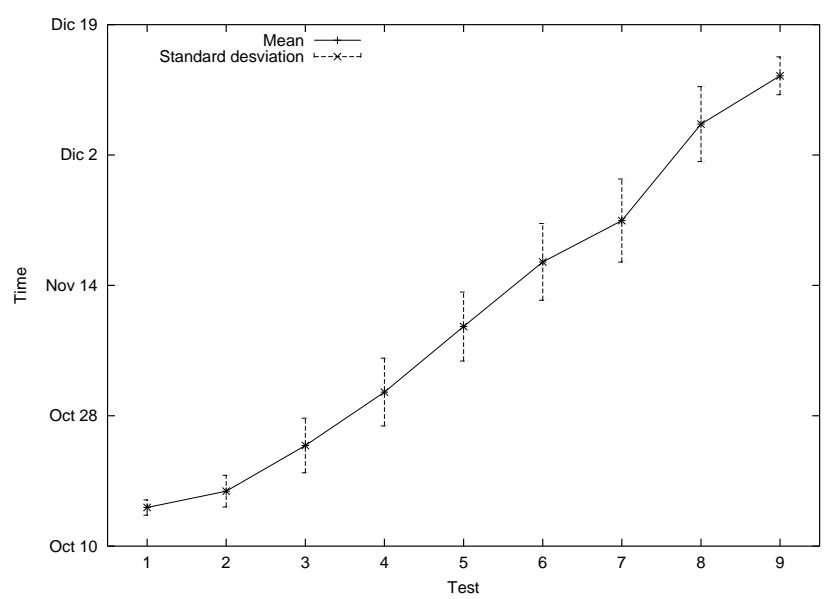

Fig. 7. Chronograme of test completions

contents can be reviewed by the student during lecture hours and during these hours the professor is available to answer any doubt face to face. This proximity to the professor makes the other electronic communication methods less used. This means that the figure of the professor in person should not disappear. This methodology has been used in an "Internet Technologies" course and the results have been presented. A special tool adapted to this course has been shown, highlighting its new functionalities like accounting the time for test completion and using it to grade the students. This parameter has allowed us to distinguish between different kinds of students and assign different profiles to them. With this study it is easy to choose a threshold to penalize the grade of students that take too much time to finish certain tests.

\section{REFERENCES}

[1] Berkeley webcast. http://webcast.berkeley.edu, 2000.

[2] Mit opencourseware. http://ocw.mit.edu, 2002.

[3] Cisco networking academy. http://cisco.netacad.net.

[4] L.R. Irons, D.J. Jung, and R.O. Keel. Interactivity in distance learning: The digital divide and student satisfaction. Educational Technology \& Society journal, 5(3), July 2002.

[5] P. Brusilovsky and P. Miller. Course Delivery Systems for the Virtual University. Access to Knowledge: New Information Technologies and the Emergence of the Virtual University. Amsterdam: Elsevier Science and International Association of Universities, 2001.

[6] WebCT e-learning solution. http://www.webct.com, 1997.

[7] M.M. Danchak and R.C. Grosser. WebCT: The Impact on Students. In WebCT 99, Vancouver, B.C., June 1999.

[8] Lotus Learning Space. http://www.lotus.com/products/learnspace.nsf/ wdocs/homepage?opendocument, 1999.

[9] M.G. Campos Pimentel, J.B. Santos Junior, and R.P. de Mattos Fortes. Tools for authoring and presenting structured teaching material in the WWW. In WebNet'98, World Conference of the WWW,Internet, and Intranet, volume pp.194-199, Orlando,FL, November 1998.

[10] Kinshuk, A. Patel, R. Oppermann, and D. Russell. Role of human teacher in web-based intelligent tutoring systems. Journal of Distance Learning, 6(1):26-35, 2001.

[11] M.A. Storey, B. Phillips, M. Maczewski, and M. Wang. Evaluating the usability of web-based learning tools. Educational Technology \& Society journal, 5(3), July 2002. 